\title{
Erratum to: 2013 SSAT Presidential Address: Peer Review
}

\author{
Jeffrey B. Matthews
}

Published online: 4 February 2014

(C) 2014 The Society for Surgery of the Alimentary Tract

\section{Erratum to: J Gastrointest Surg}

DOI 10.1007/s11605-013-2342-y

There is an error in reference 16 in this paper. The correct reference is as follows:

Beall J. Predatory publishers are corrupting open access. Nature 2012; 489: 179

The online version of the original article can be found at http://dx.doi.org/ 10.1007/s11605-013-2342-y.

J. B. Matthews $(\square)$

Department of Surgery, Division of Biological Sciences, The

University of Chicago Medicine, 5841 S. Maryland Ave. MC5029,

Chicago, IL 60637, USA

e-mail: jmatthews@surgery.bsd.uchicago.edu 